\title{
Performance Evaluation study of Hybrid Generation System (Microhydro + Diesel) in Iraqi Remote Rural Electrification
}

\author{
Prof. Dr. M. F. AL_Kababjie \\ University of Mosul \\ Collage of Engineering \\ Electrical department \\ Al_kababjie@yahoo.com
}

\author{
W. H. Hamdon \\ University of Mosul \\ Collage of Engineering \\ Electrical department \\ waelhashem_67@yahoo.com
}

\begin{abstract}
This work highlights the benefits and advantages of using Micro Hydro Power Plants (MHPP) in electrification the rural areas, which they are remote from the electric grid and locate beside the river. In these areas Electrical Energy is generated, if any, by diesel generators. This work presents the Performance evaluation and feasibility study as well as environmental effect of adding a Micro Hydro electrical generation unit to two diesel generators used for electrification an Iraqi remote village. Homer software from National Renewable Energy Laboratory (NREL) - USA is used to simulate the system to obtain the optimum hybrid power system configuration. The results of simulation show that the hybrid power system can reduce the cost of electric power unit (kilowatt / hour) as well as reducing the level of air pollution and noise compared to the stand alone diesel system.

Index Terms: Hybrid Generation System, Micro-hydropower, HOMER, Renewable energies, Rural electrification, Environmental effects.

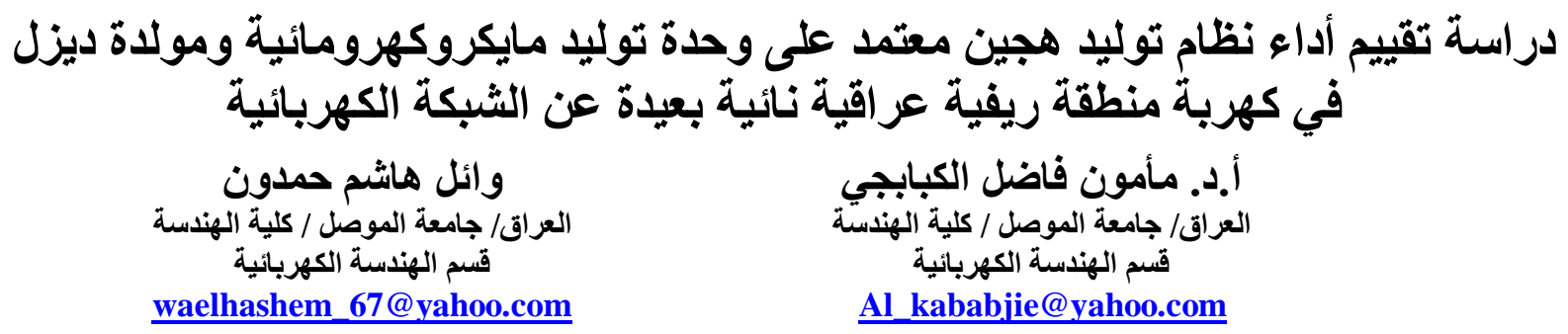

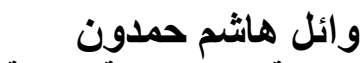

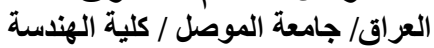

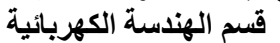

waelhashem_67@yahoo.com

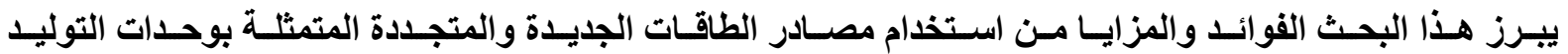

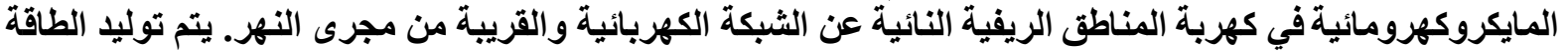

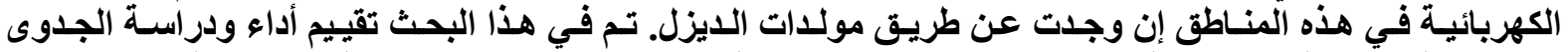

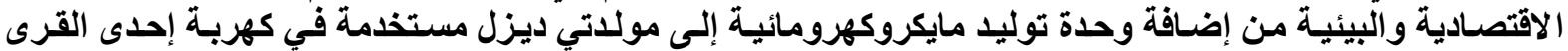

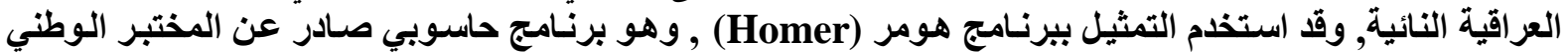

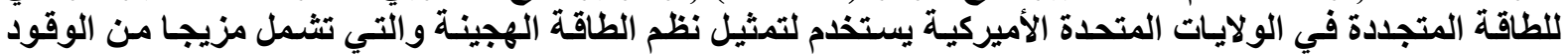

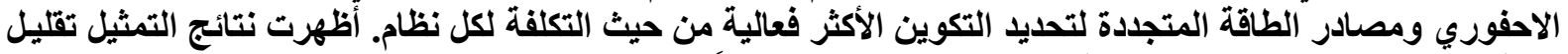

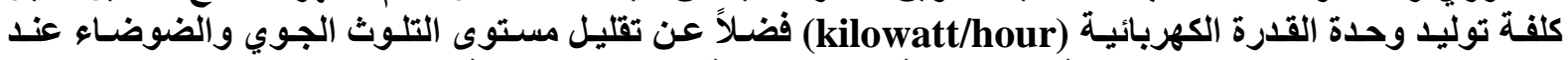

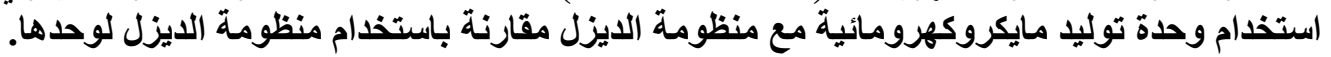




\section{Introduction}

Many of Iraqi villages are using the diesel generators due to their remote locations from Iraqi electric grid lines.

The diesel generator presents the advantages of having low investment costs and being easy to operate. Against these advantages the diesel generators present some disadvantages as listed below [1]:

1- The operating and maintenance costs are high because of the consumption of fuel and lubrication.

2- The Environmental impacts:

Air pollution: Carbon dioxide emissions (CO2) contribute to global warming. Compounds that can cause cancer or mutations can be formed during combustion and are spread through exhaust gases. Oxide of nitrogen (NOX) and non-combusted carbon hydrogen compounds $(\mathrm{CH})$ can also be harmful to health as they generate ozone. SO2 and NOX may create problems of acidification.

Noise: High noise levels can be a problem for the neighbors, as well as for the operators. Being exposed to $85(\mathrm{~dB})$ for more than 4 hours per day increases the risk of getting permanent hearing loss.

Oil spillage: Fuel and lubricants pollute the soil and water.

- The efficiency of the system: Of the chemical bounded energy in the fuel, about $30 \%$ is converted to electric energy. The rest of energy is lost as heat.

Thus there is a need to supply the load with more efficient, cleaner and cost-effective technologies such as renewable energy resources.

Renewable energy or "green energy" is defined as the energy generated from natural resources and Iraq has a variety of renewable energy resources such as solar, wind and kinetic energy of water flow of Tigris and Euphrates rivers and their tributaries and branches which can by efficiently employed to solve electricity supply shortage. Hybrid power systems usually integrate renewable energy sources with fossil fuel based generators to provide electrical power. They are generally independent of large electric grids and are used to feed loads in remote areas. Hybrid systems offer better performance, flexibility of planning and environmental benefits compared to the diesel generator based stand-alone system. Hybrid systems also give the opportunity for expanding the generating capacity in order to cope with the increasing demand in the future [2].

\section{Il. HOMER program}

HOMER Software is a flexible tool that models a mix of conventional fuels and renewable energy to determine the most cost-effective configuration for each system. HOMER is an abbreviation of "Hybrid Optimization Model for Electric Renewables" [3]. It is a computer model proposed by the National Renewable Energy Laboratory (NREL) for evaluating design options for bothoff-grid and grid-connected power systems. It can be employed for standalone, remote, and distributed generation applications. Its optimization and sensitivity analysis algorithms allow to evaluate the economic and technical feasibility of a large number of technology options and to account for variation in technology costs and energy resource availability. HOMER simulates the operation of a system by making energy balance calculations in each time step of the year. For each time step, HOMER compares the electric and thermal demand in that time step to the energy that the system can supply in that time step, and calculates the flows of energy to and from each component of the system. 
HOMER performs these energy balance calculations for each system configuration. It then determines whether a configuration is feasible, i.e., whether it can meet the electric demand under the conditions that you specify, and estimates the cost of installing and operating the system over the lifetime of the project. The system cost calculations account for costs such as capital, replacement, operation and maintenance, fuel, and interest. After simulating all of the possible system configurations, HOMER displays a list of configurations, sorted by net present cost (sometimes called lifecycle cost), to compare system design options. HOMER calculates the total net present cost (\$) with equation (1).

$$
N P C=\frac{C_{a n n}}{C R F\left(i, R_{p r o j}\right)}
$$

Where:

$C_{a n n}$ is the total annualized cost $(\$ / y r)$.

$\mathrm{CRF}$ is the capital recovery factor, which in turn is a function of the interest rates i (\%) and the project lifetime $R_{p r o j}(\mathrm{yr})[4]$.

Another important factor for simulations is the cost curve. For a desired number of discrete simulated power values, it must be defined how the input costs will vary. These costs are related to capital, replacement and operation and maintenance (O\&M). Therefore, for every renewable source, it must be selected the power range and its associated costs. Fig. 1 illustrates an example of a cost curve. The power range goes from zero upto $\mathbf{3 , 2 5 0} \mathrm{kW}$ (dispatch intervals of $250 \mathrm{~kW}$ ). So, one discrete cost value for replacement and initial capital is chosen for each possible (combination of) simulated power.

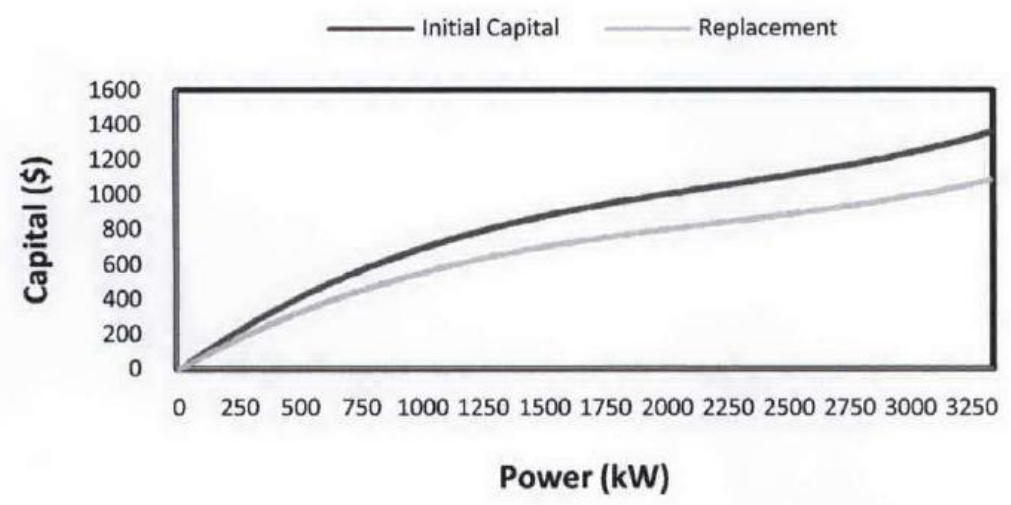

Figure (1): Example of a cost curve for Homer [4]

\section{Micro-hydro power system}

Micro-Hydro power system (MHPS) is one of the popular renewable energy sources in the developing countries. Most of the MHPS operate in isolated mode supplying the electricity in the local rural area where the population is very small and sparsely distributed and the extension of grid system is not financially feasible because of high cost investment required for transmission line [5].

Micro-hydropower systems general benefits are [6]:

- Hydroelectric energy is renewable electrical energy source with a high capacity factor

- Significant potential for Green House Gases GHG emission reduction 
- Hydroelectric energy has no fuel cost and with low operating and maintenance costs, it is essentially inflation proof

- Hydroelectric stations have a long life and many existing stations have been in operation for more than half a century and are still operating efficiently

- Hydropower plants have achieved excellent efficiency making it the most efficient of energy conversion technologies

- Majority of micro-hydropower would be run-of-river system, no flooding of land

- Development of micro-hydropower would benefit local economy

- Significant potential in Iraq

Hydro power is very site specific and micro-hydro schemes are smaller in size and they refer to systems with capacity ranging from $1 \mathrm{~kW}$ just enough to provide domestic lighting to a group of houses through a battery charging to $100 \mathrm{~kW}$ which can be used for small factories and to supply an independent local mini-grid but do not necessarily supply electricity to the national grid [2]. These small units have been used for many years, especially for their mechanical power, but recent increases in the value of electrical energy and incentive programs have made the construction and development of micro-hydro power plants much more attractive. For villages very far from the national grid where connection to it may not be economical and for which a constant stream flow is available, micro hydro-power systems are the best options for electrification

The components for a MHP system can be grouped in to civil work components and electromechanical components, as shown in Figure 2 below. These components are presented in detail in the following subsections.

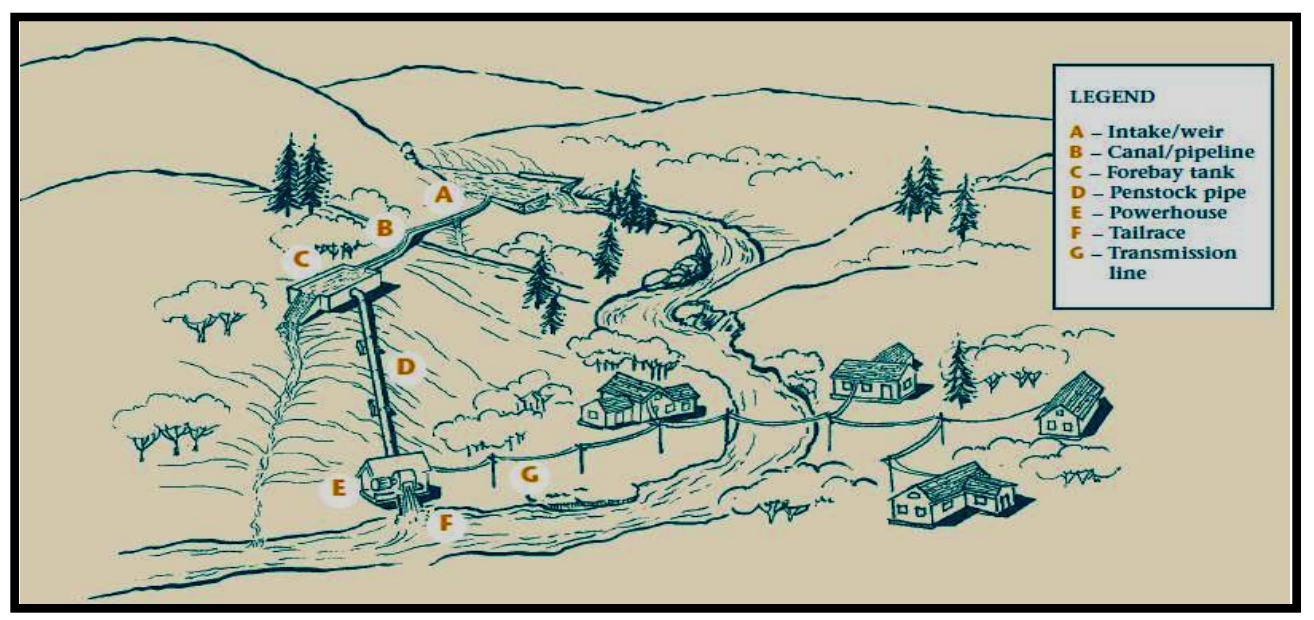

Figure (2): Principal components of a micro-hydropower system [7].

A. An intake where the water is diverted from a steam.

B. A head race to transport the water to a fore bay tank just above the power house through a canal or pipe.

C. A fore bay tank to collect the water and screen out debris before it is transported to the turbine.

D. A penstock pipe to transport the water from the fore bay tank to the power house.

E. Power house which consist of:

- A turbine to convert the power of the falling water into mechanical rotational power.

- A generator to convert the mechanical power to electricity.

- A controller to maintain a constant load on the generator.

F. A tailrace to return the used water to the steam. and 
G. Transmission and distribution lines to the users.

For the specific site selected in this study, the two important data assessed are the gross head is $(3 \mathrm{~m})$, and the flow of the water is $\left(1000 \mathrm{l} / \mathrm{s}\right.$ or $\left.1 \mathrm{~m}^{3} / \mathrm{s}\right)$. The potential electrical power available from the water resource is $20.6 \mathrm{~kW}$ given by the following equation [7]:

$\mathbf{P}=\mathbf{Q} * \mathbf{H} * \mathbf{g} * \mathbf{e}$

Where:

$\mathrm{P}=$ potential electrical power in $\mathrm{kW}$

$\mathrm{Q}=$ Usable flow rate in $\mathrm{m}^{3} / \mathrm{s}$

$\mathrm{H}=$ Gross head in $\mathrm{m}$

$\mathrm{g}=$ Gravitational constant $\left(9.81 \mathrm{~m} / \mathrm{s}^{2}\right)$

$\mathrm{e}=$ efficiency factor

According to the hydrology and topology of the area a Kaplan turbine (small in size and faster) can be selected. We will assume that the efficiency of the turbine depends on the manufacturer, and is about 0.75 .

For variable speed generation, the choice of an induction generator is considered attractive due to its flexible rotor speed characteristic in contrast to the constant speed characteristic of a synchronous generator. The generator efficiency is usually more than 0.9 [8].

According to the local prices The estimated initial capital cost of the proposed Micro Hydro Power Plant is (\$50000) where the operation and maintenance cost per year is (\$1200) and the life time is expected to last for (25 Year) and the interest rate is $6 \%$.

\section{System components and simulation}

The proposed system contains micro hydro Power Plant subsystem and diesel generators unit sub-system. To design a mini-grid hybrid power system, some information must be obtained from a particular remote location such as the load profile that should be met by the system, the average steam flow available to the hydro turbine each month, initial cost for each component (diesel, renewable energy generators), cost of diesel fuel, annual interest rate, project lifetime, etc[9].

For this work, we select one of remote villages in Al-Gowair region north Iraq, which locate beside the Great Zab one of the Tigris river tributaries, this village is sparsely distributed. It is populated by approximately 280 people. Now the electrical power supply is maintained by operating 2 diesel generators with the capacity of $50 \mathrm{~kW}$ and $25 \mathrm{~kW}$.

According to the information obtained from the local area of the village, the estimated load profile is shown as in Figure 3. This primary load has annual average of $533 \mathrm{kWh} /$ day with annual peak of $72 \mathrm{~kW}$.

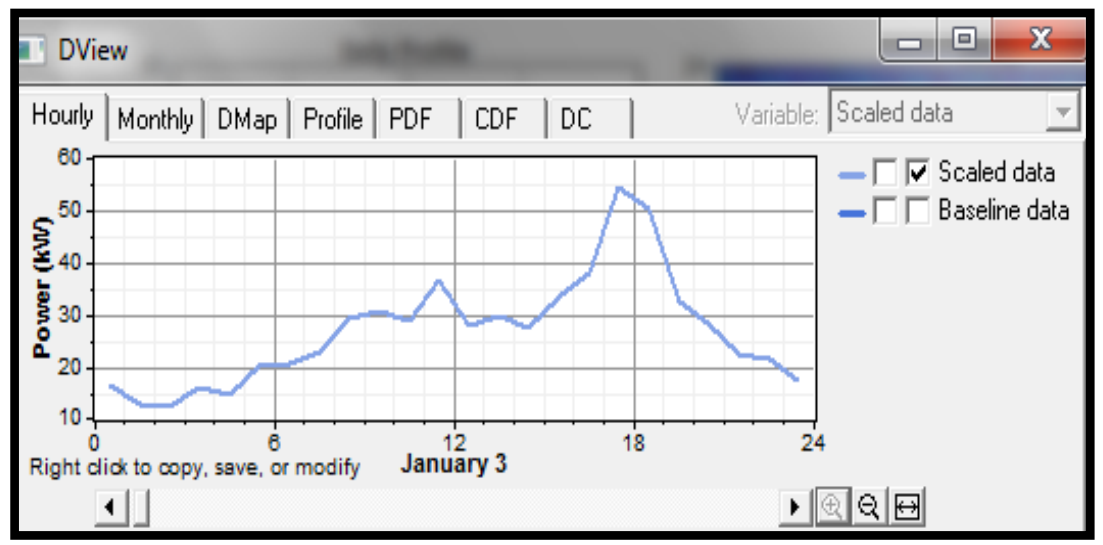

Figure 3: Estimated daily load profile 
According to the local area prices The costs and performance characteristics of a $(25 \mathrm{~kW})$ generator are (\$10000) initially, (\$8000) to replace it at the end of its life, and (\$0.8) per hour for operation and maintenance. The lifetime hours that the generator will run before needing replacement are (35000 hours).

The costs and performance characteristics of a $(50 \mathrm{~kW})$ generator are (\$15000) initially, (\$9000) to replace it at the end of its life, and (\$1.5) per hour for operation and maintenance. The lifetime hours that the generator will run before needing replacement are (40000 hours). Fuel price is $0.7 \$ / \mathrm{L}$.

The system is simulated by Homer program which gives all possible configurations and arranged them according to the basis of the NPC (net present cost).

The overall system configuration of the proposed mini-grid hybrid system is shown in Figure 4.

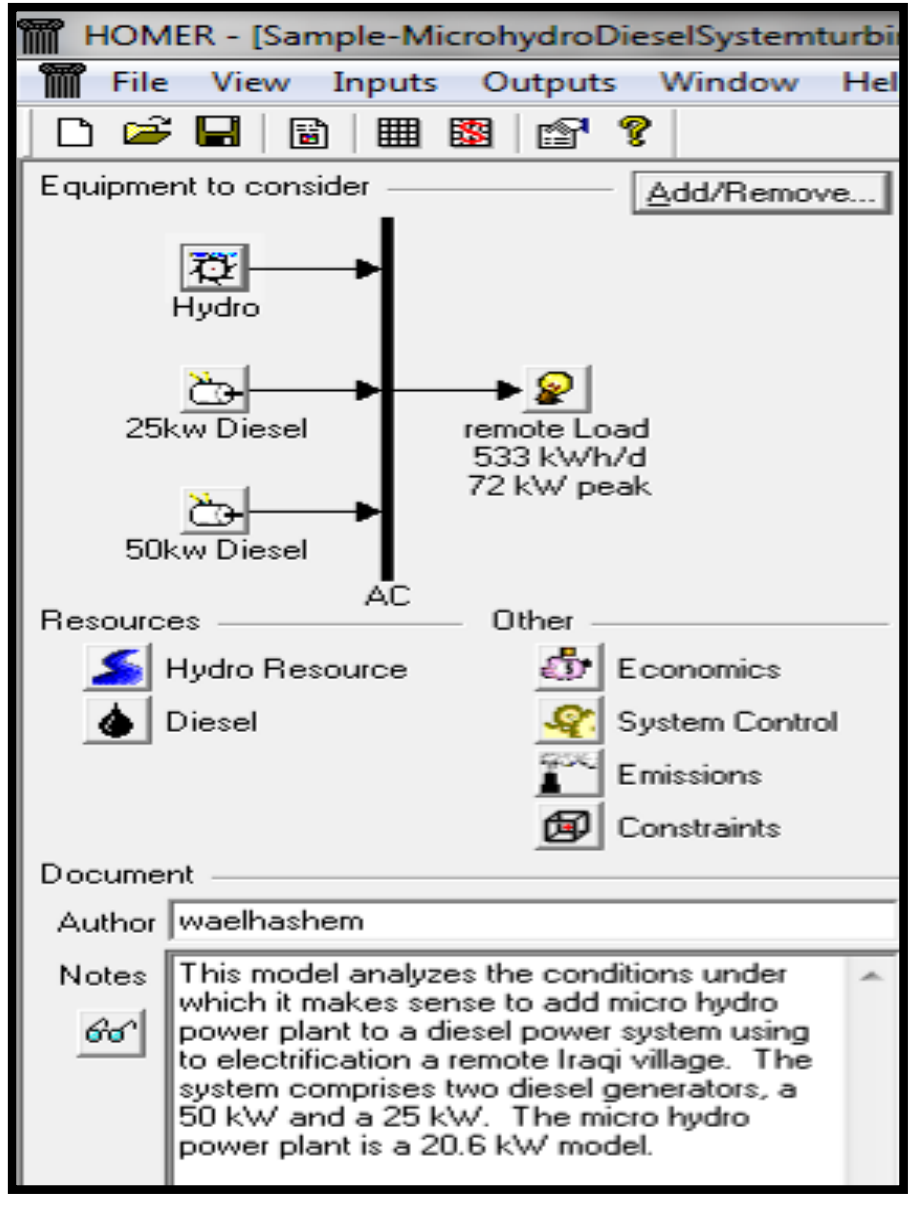

Figure (4): Proposed scheme of Hybrid power system for the study area in Homer software

\section{V simulation results and discussion}

The simulation results by Homer software are shown in fig (5). As results of simulation, the micro hydro power plant and diesel generators were evaluated to determine the feasibility of the system. MHPP designed to operate continuously as long as continuous water flows.

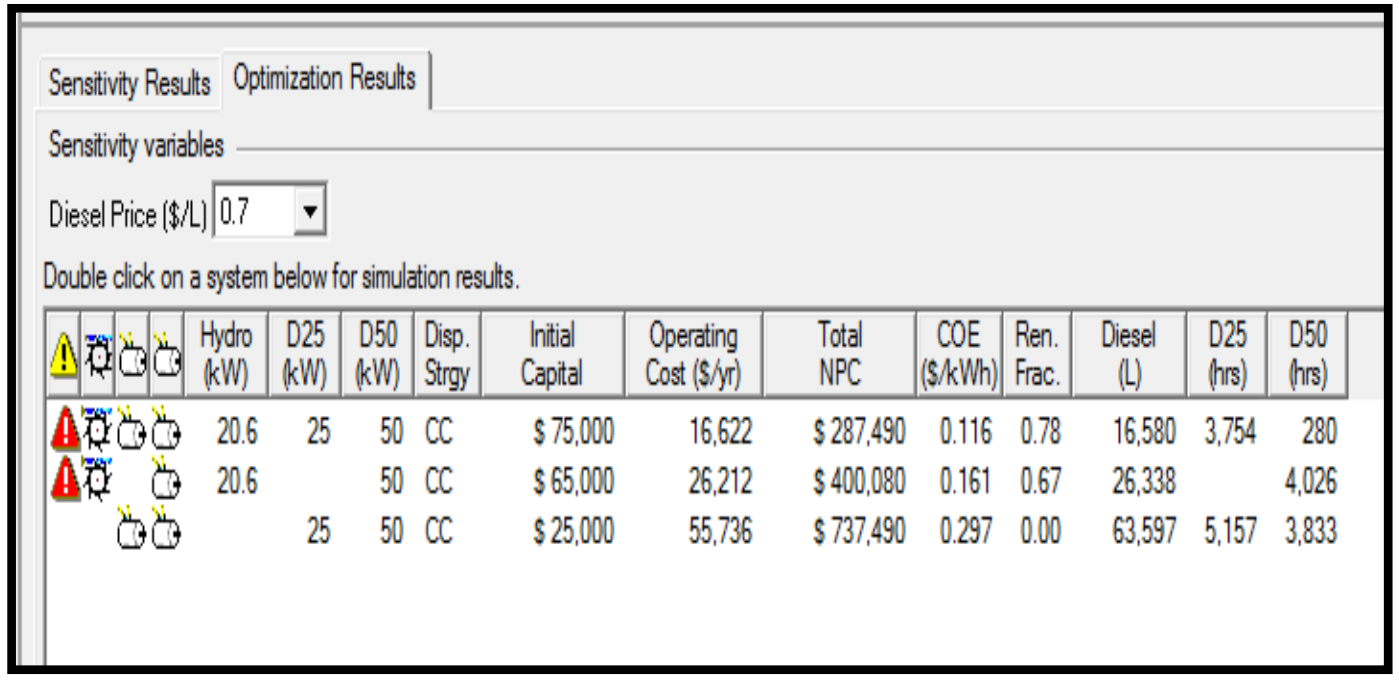

Figure (5): The simulation results of the proposed system. 


\section{Economic feasibility}

For the optimum solution of the proposed model (Two diesel Generator 50\&25kW with MHPP) the COE (cost of energy) is found to be $\$ 0.116 / \mathrm{kWhr}$ which is lower than the COE when using 50kW diesel Generator With MHPP and Two diesel Generator 50\&25kW without MHPP. Table 1 shows the comparison of simulation results for the three different configurations

Table (1): the comparison of simulation results for the three different conditions.

\begin{tabular}{|c|c|c|c|}
\hline variable & $\begin{array}{c}\text { Two diesel Generator } \\
\mathbf{5 0 \& 2 5 k W} \text { Without } \\
\text { MHPP }\end{array}$ & $\begin{array}{c}\text { 50kW diesel } \\
\text { Generator } \\
\text { With MHPP }\end{array}$ & $\begin{array}{c}\text { Two diesel Generator } \\
\mathbf{5 0 \& 2 5 k W} \\
\text { With MHPP }\end{array}$ \\
\hline Initial cost & $\$ 25,000$ & $\$ 65000$ & $\$ 75000$ \\
\hline Total net present cost & $\$ 737490$ & $\$ 400080$ & $\$ 287490$ \\
\hline Levelized cost of energy & $\$ 0.297 / \mathrm{kWh}$ & $\$ 0.161 / \mathrm{kWh}$ & $\$ 0.116 / \mathrm{kWh}$ \\
\hline Operating cost & $\$ 55736 / \mathrm{yr}$ & $\$ 26212 / \mathrm{yr}$ & $\$ 16622 / \mathrm{yr}$ \\
\hline Fuel cost & $\$ 569087$ & $\$ 235684$ & $\$ 148368$ \\
\hline
\end{tabular}

\section{Greenhouse gases (GHG) reduction}

Recently, the world concerns the reduction of greenhouse gases in order to minimize the pollution of gas emission. HOMER uses the emissions coefficients, which are in units of grams of pollutant emitted per quantity of fuel consumed, to calculate the emissions of six pollutants. The combination of MHPP and diesel generator able to reduce the pollution of gas emission compared to a system that only consisting of diesel system. The greenhouse gases pollute the environment which eventually affects the life of human beings [10]. The results of simulation show that the two diesel generators used at this area now adds a total of 167471 $\mathrm{kg} / \mathrm{yr}$ of $\mathrm{CO}_{2}$ pollutants into the atmosphere of the village. The proposed hybrid system with MHPP can reduce the $\mathrm{CO}_{2}$ emission to $43662 \mathrm{~kg} / \mathrm{yr}$. The concentrations of other pollutants such as $\mathrm{CO}$, sulfur dioxide $\left(\mathrm{SO}_{2}\right)$, nitrogen oxides $\left(\mathrm{NO}_{\mathrm{x}}\right)$, etc. for diesel and hybrid system are summarized in Table 2.

Table (2). Green house gases for diesel and hybrid systems

\begin{tabular}{|c|c|c|c|c|}
\hline variable & Description & $\begin{array}{c}\text { Two diesel } \\
\text { Generator } \\
\text { 50\&25kW } \\
\text { Without MHPP }\end{array}$ & $\begin{array}{l}\text { 50kW diesel } \\
\text { Generator } \\
\text { With } \\
\text { MHPP }\end{array}$ & $\begin{array}{l}\text { Two diesel } \\
\text { Generator } \\
\text { 50\&25kW } \\
\text { With MHPP }\end{array}$ \\
\hline Pollutant & & \multicolumn{3}{|c|}{ Emissions $(\mathrm{kg} / \mathrm{yr})$} \\
\hline $\begin{array}{l}\text { Carbon dioxide } \\
\quad\left(\mathrm{CO}_{2}\right)\end{array}$ & Nontoxic greenhouse gas. & 167471 & 69357 & 43662 \\
\hline $\begin{array}{c}\text { Carbon } \\
\text { monoxide(CO) }\end{array}$ & $\begin{array}{l}\text { Poisonous gas produced by incomplete } \\
\text { burning of carbon in fuels. }\end{array}$ & 413 & 171 & 108 \\
\hline $\begin{array}{l}\text { Unburned } \\
\text { hydocarbons } \\
\text { (UHC) }\end{array}$ & $\begin{array}{l}\text { Products of incomplete combustion of } \\
\text { hydrocarbon fuel, including } \\
\text { formaldehyde and alkenes. }\end{array}$ & 45.8 & 19 & 11.9 \\
\hline $\begin{array}{l}\text { Particulate } \\
\text { matter (PM) }\end{array}$ & $\begin{array}{c}\text { A mixture of smoke, soot, and liquid } \\
\text { droplets }\end{array}$ & 31.2 & 12.9 & 8.12 \\
\hline $\begin{array}{l}\text { Sulfur dioxide } \\
\quad\left(\mathrm{SO}_{2}\right)\end{array}$ & $\begin{array}{l}\text { A corrosive gas released by the burning } \\
\text { of fuels containing sulfur }\end{array}$ & 336 & 139 & 87.7 \\
\hline $\begin{array}{l}\text { Nitrogen } \\
\text { oxides }\left(\mathrm{NO}_{\mathrm{x}}\right)\end{array}$ & $\begin{array}{l}\text { Various nitrogen compounds like } \\
\text { nitrogen dioxide }\left(\mathrm{NO}_{2}\right) \text { and nitric oxide } \\
\text { (NO) formed when any fuel is burned at } \\
\text { high temperature. }\end{array}$ & 3689 & 1528 & 962 \\
\hline
\end{tabular}




\section{Conclusions}

Hybrid systems are one of the most promising applications of renewable energy technologies in remote areas, where the cost of grid extension is high. By using HOMER (a software from National Renewable Energy Laboratory (NREL) - USA), This paper presents the economical feasibility and environmental effect for adding Micro Hydro Power Plant into an existing diesel system to meet the load requirement in one of remote villages in Al-Gowair region north Iraq. The results show that the cost of generating electric power unit (kilowatt / hour) is decrease from $\$ 0.297 / \mathrm{kWh}$ to $\$ 0.116 / \mathrm{kWh}$ and the Total net present cost is decrease from $\$ 737490$ to $\$ 287490$ as well as reducing the level of air pollution and noise.

\section{References}

1. K. Kusakana, J.L. Munda "Economic and Environmental Analysis of Micro Hydropower System for Rural Power Supply",IEEE 2nd International Power and Energy Conference in 2008 PP: 441-444.

2. E. A. Al-Ammar, N. H. Malik, M. Usman, "Application of Using Hybrid Renewable Energy in Saudi Arabia", ETASR- Engineering, Technology \& Applied Science research, Vol. 1, No. 4, 2011, pp. 84-89.

3. Mohammad Saad Alam, David W. Gao, " Modeling and analysis of a Wind/ PV/ Fuel Cell Hybrid power system in HOMER", 2nd IEEE Conference on Industrial Electronics and Applications in 2007 Pages: 1594-1599.

4. B.Wottrich, L.Neves Canha, R.Cezar , "Economic Analysis for Management of Distributed Generation Systems on Electrical Networks", 2009 6th International Conference on the European Energy Market Year:2009Pages: 11461-1146

5. Dr. R. K. Saket, " Design, Development and Reliability Evaluation of Micro Hydro Power Generation System Based on Municipal Waste Water", 2008 IEEE Canada Electric Power Conference Year: 2008 Pages: 1-8.

6. Ranjitkar,G. Jinxing Huang Tung, T. "Application of Micro-hydropower Technology for Remote Regions", Journal: 2006 IEEE EIC Climate Change Conference ISBN: 1424402182 Year: 2006 Pages: 1-10

7. "Micro-Hydropower Systems: A Buyer's Guide", Natural Resources Canada 2004, ISBN $0-662-35880-5$

8. K. Kusakana, J.L. Munda, "Feasibility study of a hybrid PV-Micro Hydro system for rural electrification", Journal: AFRICON 2009 Year:2009 Pages:1-5 Provider: IEEE Publisher.

9. D.K. Lal, B. B. Dash, "Optimization of PV/Wind/Micro-Hydro/Diesel Hybrid Power System in HOMER for the Study Area", International Journal on Electrical Engineering and Informatics Volume 3, Number 3, 2011.

10. Al-Badi, A.H. Bourdoucen," Economic Analysis of Hybrid Power System for Rural Electrification in Oman", Journal: 2009 2nd International Conference on Adaptive Science \& amp ;Technology (ICAST)ISSN: 08558906 Year: 2009 Pages: 284289.Provider: IEEE Publisher.

The work was carried out at the college of Engineering. University of Mosul 


\section{Biographies}

Prof. Maamoon F. Al-Kababjie was born in Mosul, Iraq in June 1947.He received his B.Sc. In Elect. Eng. from University of Mosul June, 1968, M.Sc. In Elect. Eng. from METU, Turkey March, 1976 and Ph.D. In Elect. Eng. From University of Bradford, U.K. 1982. He is a Prof. at the Faculty of Electrical Engineering and currently appointed as the Head of Electrical Engineering Department, University of Mosul. Iraq. He has written more than 40 technical papers and also supervising 22 postgraduate students. His research interest includes power system stability and protection, voltage profile studies, artificial neural network. Fuzzy logic, renewable energy systems

Wael H. Hamdon was born in Mosul, Iraq in March 1967. He received his B.Sc., M.Sc In Elect. Eng. from University of Mosul 1990, 2007 respectively. He is currently pursuing his $\mathrm{PhD}$ degree. His major research interest include islanding operation of distributed generation, Micro Hydro Power Plant system, electrical Quality. 
